\title{
A REALIZAÇÃO DE SUJEITOS E OBJETOS PRONOMINAIS NO PORTUGUÊS URUGUAIO
}

LA REALIZACIÓN DE SUJETOS Y OBJETOS PRONOMINALES EN PORTUGUÉS URUGUAYO

\author{
THE REALIZATION OF PRONOMINAL SUBJECTS AND OBJECTS IN URUGUAYAN \\ PORTUGUESE
}

Leonor Simioni*

Universidade Federal do Pampa

\begin{abstract}
RESUMO: O objetivo do trabalho é descrever a realização de sujeitos e objetos pronominais no português uruguaio (PU) a partir de um corpus de dados orais. Enquanto o português brasileiro (PB) apresenta em torno de $80 \%$ de sujeitos pronominais preenchidos, no PU há 50\% de sujeitos referenciais nulos, com preferência de preenchimento para a $1^{a}$ pessoa do singular e predominância de nulos especialmente na $1^{\mathrm{a}}$ pessoa do plural. Os objetos podem ser realizados como clíticos (incluindo a $3^{\mathrm{a}}$ pessoa) ou como pronomes retos. A colocação dos clíticos apresenta próclise categórica aos verbos flexionados e gerúndio e ênclise com infinitivos e imperativos, além de subidas de clítico e redobro de clíticos. Objetos anafóricos podem ser retomados por nulos, clíticos ou pronomes retos, estando a retomada condicionada a traços semânticos do antecedente. Tanto na posição de sujeito quanto na posição de objeto, pronomes retos de $3^{\text {a }}$ pessoa ocorrem somente com referentes humanos. Os dados confirmam a existência de diferenças sintáticas significativas entre PU e PB.
\end{abstract}

PALAVRAS-CHAVE: Português uruguaio. Sujeito pronominal. Objeto pronominal.

RESUMEN: El objetivo de este trabajo es describir la realización de sujetos y objetos pronominales en el portugués uruguayo a partir de un corpus de datos orales. Mientras que el portugués brasilero presenta alrededor de un $80 \%$ de sujetos pronominales expresos, en PU hay un 50\% de sujetos referenciales nulos, cuya expresión es favorecida por la primera persona del singular y desfavorecida por la primera persona del plural. Los objetos pueden realizarse como clíticos (incluyendo los de tercera persona) o como pronombres sujetos. La colocación de los clíticos es siempre proclítica con verbos flexionados y gerundio, y enclítica con infinitivos e imperativos. Además, hay subida de clíticos y doplado de clíticos. Objetos anafóricos pueden ser retomados por nulos, clíticos o pronombres sujetos, dependiendo de los rasgos semánticos de los elementos antecedientes. Tanto en la posición de sujeto como en la posición de objeto, los pronombres sujetos de tercera persona ocurren únicamente con referentes humanos. Los datos confirman la existencia de importantes diferencias sintácticas entre PU y PB.

PALABRAS CLAVE: Portugués uruguayo. Sujetos pronominales. Objetos pronominales.

ABSTRACT: The aim of the paper is to describe the realization of pronominal subjects and objects in Uruguayan Portuguese (UP) in an oral corpus. While Brazilian Portuguese (BP) has around $80 \%$ of overt pronominal subjects, UP has only $50 \%$. The $1^{\text {st }}$ person singular is mostly overt, while the $1^{\text {st }}$ person plural is mostly null. Objects can be clitics (including $3^{\text {rd }}$ person), null or strong pronouns. Clitic placement involves clitics categorically preceding inflected and gerund verbs and following infinitives and imperatives, as well as clitic climbing and clitic doubling. Anaphoric objects can be null or resumed by clitics or strong pronouns,

* Mestre em Linguística pela Universidade Federal de Santa Catarina e doutora em Linguística pela Universidade de São Paulo. Professora adjuntada UniversidadeFederaldoPampa,campus Jaguarão. E-mail: simionileonor@gmail.com. 
depending on the semantic features of the antecedent. Both in subject and object positions, strong $3^{\text {rd }}$ person pronouns can occur only with human antecedents. Data confirm the existence of significant syntactic differences between UP and BP.

KEYWORDS: Uruguayan Portuguese. Pronominal subjects. Pronominal objects.

\section{INTRODUÇÃO}

O português uruguaio (PU), falado ao norte do Uruguai como língua materna, foi, por muito tempo, tratado como uma "mistura" entre português e espanhol, originada do contato entre essas línguas propiciado pelas condições históricas de povoamento da região, em vista da ocupação portuguesa e da fixação de muitas famílias portuguesas no território uruguaio (ELIZAINCÍN, 1979, p. 13). Ainda que a partir da segunda metade do século XIX tenha havido um esforço por parte do governo uruguaio para deter o avanço do português, originando uma situação de diglossia (BEHARES, 2007), o português permanece presente no território uruguaio, nas faixas próximas à fronteira com o Brasil.

Elizaincín, Behares e Barrios (1987), pioneiros na descrição gramatical dessa variedade, reconhecem a presença de características próprias no português uruguaio, ${ }^{1}$ mas analisam-no em termos de traços morfossintáticos classificados como tendência ao português e tendência ao espanhol, evidenciando a concepção de "mescla”. Mais recentemente, Carvalho (2003, p. 133) rejeita esse tratamento e define o PU como "[...] um dialeto do português de características rurais que sofre influências do espanhol", cuja variabilidade deve-se ao fato de que qualquer sistema linguístico está sujeito a variação, condicionada por fatores linguísticos, sociais e estilísticos. Para Carvalho (2003), o português falado no Uruguai oscila em um contínuo entre o português brasileiro urbano e o português uruguaio rural. ${ }^{2}$ Além disso, a maioria dos falantes são bilíngues português/espanhol (CARVALHO, 2003; PACHECO, 2013).

A existência de uma variedade do português falada como língua materna por uruguaios bilíngues tem fomentado pesquisas em que se investiga a presença de características sintáticas do português brasileiro no português uruguaio, bem como as possíveis influências da pressão do espanhol sobre a gramática do PU. Os resultados dessas investigações (BOTTARO, 2009; MUNIZ, 2017; GASQUE DE SOUZA; CHAVES; SIMIONI, 2018) têm evidenciado diferenças consideráveis entre PU e PB no que diz respeito à sintaxe, que apontam para línguas-I distintas. Ao mesmo tempo, trabalhos como o de Carvalho e Bessett (2015), que analisa a expressão do sujeito pronominal na fala de bilíngues $\mathrm{PU} /$ espanhol, mostram que, contrariando as expectativas, não parece haver convergência entre as gramáticas dessas duas línguas. Esses resultados, tomados em conjunto, levam à conclusão de que o PU é um sistema independente.

Nesse cenário, este artigo discute a realização de sujeitos e objetos pronominais no PU. A seleção desses tópicos dá-se em função de serem pontos em que as gramáticas do $\mathrm{PB}$ e do espanhol se distanciam. Interessa-nos descrever a gramática do PU, oferecendo pontos de comparação com o PB e, na medida do possível, com o espanhol. ${ }^{3}$ Além disso, esperamos, com os resultados desta investigação, corroborar os achados mencionados acima, contribuindo para a caracterização do PU como uma língua-I com características próprias, distinta tanto do PB quanto do espanhol.

\section{METODOLOGIA DA PESQUISA}

Para a realização da pesquisa, analisamos os dados do corpus do projeto Rumo a uma gramática do português uruguaio, desenvolvido na Universidade Federal do Pampa (campus Jaguarão). O corpus, em fase de constituição, está composto atualmente por entrevistas realizadas com quatro informantes residentes em Rio Branco e oriundos de Poblado Uruguay, um pequeno povoado rural

\footnotetext{
${ }^{1}$ Os autores referem-se a essa variedade como Dialectos portugueses en Uruguay (DPU), terminologia que reflete o reconhecimento de sua base portuguesa.

${ }^{2}$ De modo geral, falantes de zonas mais urbanas tendem ao português brasileiro urbano, enquanto falantes de zonas rurais tendem ao português uruguaio rural.

${ }^{3}$ A comparação com o espanhol será feita a partir da literatura. Buscar-se-ão dados do espanhol uruguaio; na ausência destes, consideraremos também dados do espanhol rio-platense.
} 
localizado no departamento de Cerro Largo, a 76km de Melo (capital do departamento) e 30km de Jaguarão/RS. Segundo dados do último Censo, Poblado Uruguay conta com aproximadamente 100 habitantes (URUGUAY, 2011).

Os informantes têm entre 37 e 83 anos, cresceram no meio rural, têm escolaridade entre o $1^{\circ}$ ano incompleto e o $6^{\circ}$ ano e são bilíngues. As entrevistas envolvem diálogo entre informante e documentador e são semiestruturadas, versando tipicamente sobre aspectos da vida dos informantes, como lembranças da infância, vida no campo e na fronteira, experiências de escolarização, rotina familiar. Também são tema da entrevista a língua falada no seio da família e na comunidade, de modo a garantir que todos os informantes tenham o português como língua materna e avaliar suas atitudes em relação ao brasilero e ao uruguayo. Os resultados são apresentados a seguir.

\section{SUIEITOS PRONOMINAIS}

Talvez uma das diferenças mais significativas entre PB e espanhol diga respeito ao preenchimento de sujeitos pronominais: enquanto as diferentes variedades diatópicas do espanhol apresentam um índice de sujeitos pronominais preenchidos em torno de $30 \%,{ }^{4}$ no $\mathrm{PB}$ os resultados das pesquisas giram em torno da casa dos $70 \% .{ }^{5}$ Não há muitos dados em relação ao preenchimento de sujeitos pronominais no espanhol uruguaio; Carvalho e Bessett (2015), investigando o espanhol falado por bilíngues na cidade fronteiriça de Rivera, encontraram uma taxa de 25\% de sujeitos preenchidos; Muniz (2017), em levantamento feito com monolíngues da cidade fronteiriça de Rio Branco, encontrou 32\% de preenchimento.

Bottaro (2009) e Carvalho e Bessett (2015), analisando o PU falado em Rivera, encontraram, respectivamente, 47\% e 46\% de sujeitos preenchidos. No corpus sob análise, encontramos taxas semelhantes: 50\% de sujeitos nulos referenciais. ${ }^{6}$ À luz desses resultados, Chaves, Souza e Simioni (2018) mostram que o PU tem propriedades compatíveis com línguas de sujeito nulo e não conta com estruturas inovadoras do $\mathrm{PB}$ cujo surgimento tem sido atribuído à mudança em direção a um sistema não pro-drop por autores como Kato e Duarte (2017), como o preenchimento de sujeitos não referenciais via alçamento de constituintes e estruturas de redobro pronominal do sujeito.

O rol dos pronomes sujeito do PU apresenta seis formas, como ilustra o Quadro 1:

\begin{tabular}{c|c|c} 
& singular & plural \\
\hline $1^{\mathrm{a}}$ & eu & nós \\
\hline $2^{\mathrm{a}}$ & tu & vocês \\
\hline $3^{\mathrm{a}}$ & ele/ela & eles/elas
\end{tabular}

Quadro 1: Pronomes sujeito no PU

Fonte: elaboração própria

\footnotetext{
${ }^{4}$ Dados apresentados por Duarte e Silva (2016) apontam 76\% de sujeitos pronominais nulos no espanhol europeu e 68\% no espanhol argentino, enquanto Carvalho e Bessett (2015) apontam 21\% de sujeitos preenchidos no espanhol de Madrid e 29\% no espanhol argentino. Carvalho (2016) indica taxas de preenchimento para as diferentes variedades diatópicas do espanhol entre 19\% e $45 \%$.

${ }^{5} 78 \%$ em Berlinck, Duarte e Oliveira (2015), 71\% em Duarte e Silva (2016).

${ }^{6}$ Foram excluídas da análise ocorrências de sujeitos nulos com verbos no imperativo e em orações coordenadas com sujeitos correferenciais, bem como expressões cristalizadas e/ou formas verbais que funcionam como marcadores discursivos, como viste?.
} 
Os pronomes de terceira pessoa manifestam-se exclusivamente nas formas portuguesas, e também não foram encontradas as formas vos, ustedes e nosotros, do espanhol. Por outro lado, não foram encontradas nos dados do PU as formas pronominais brasileiras você e a gente, ${ }^{7}$ cujo surgimento tem sido apontado como a causa da mudança do PB de uma língua pro-drop em direção a uma língua não pro-drop, devido à consequente redução no paradigma flexional (ver Quadro 2).

A esse quadro pronominal associa-se um paradigma flexional rico, com cinco distinções, explicitado no Quadro 2, abaixo, em que também se apresentam os paradigmas do PB e do espanhol uruguaio, para comparação:

\begin{tabular}{c|c|c|c|c}
\multicolumn{2}{c|}{} & PU & PB & EU \\
\hline \multirow{4}{*}{ singular } & $1^{\mathrm{a}}$ & canto & canto & canto \\
\cline { 2 - 5 } & $2^{\mathrm{a}}$ & cantas & canta & cantás \\
\cline { 2 - 5 } & $3^{\mathrm{a}}$ & canta & canta & canta \\
\hline \multirow{5}{*}{ plural } & $1^{\mathrm{a}}$ & cantamo/-emo & canta & cantan \\
\cline { 2 - 5 } & $2^{\mathrm{a}}$ & cantam & canta $(\mathrm{m})$ & cantan \\
\cline { 2 - 5 } & $3^{\mathrm{a}}$ & cantam & canta $(\mathrm{m})$ & \\
\end{tabular}

Quadro 2: Paradigma flexional: português uruguaio, português brasileiro e espanhol uruguaio

Fonte: elaboração própria

O quadro mostra que os paradigmas do português uruguaio e do espanhol uruguaio se assemelham, por apresentarem apenas um sincretismo cada um, enquanto o paradigma do PB apresenta três ou até mesmo duas distinções (COSTA; FIGUEIREDO SILVA, 2006; DUARTE; SILVA, 2016). ${ }^{8}$ Mas, se a presença de múltiplos sincretismos no paradigma do PB, fruto das mudanças no paradigma pronominal, vem sendo relacionada à passagem de um sistema pro-drop para um sistema não pro-drop, a comparação entre os paradigmas de PU e espanhol não é suficiente para explicar a diferença quantitativa de sujeitos nulos numa e noutra língua.

Cabe salientar, a esse respeito, que a concordância entre sujeito e verbo no PU é variável, como ilustra o exemplo (1).

Nós ia, voltávamo, quando quiria volvia pras casa e depois terminamo que nos casemo.

Ainda sobre o paradigma flexional, chama a atenção a presença produtiva de infinitivos flexionados nos dados do corpus, contrariando os resultados apontados por Elizaincín, Behares e Barrios (1987):

(2) a. Quando vem o carnaval que vem as escolas de samba dançarem aqui...

b. Digo: "mãe, vai, escarva e arranca uma de cada pé" pa irmo comendo porque às vez não havia as cosa, viste?

Os dados confirmam a tendência detectada em Muniz (2017) de uma preferência de preenchimento para a $1^{\text {a }}$ pessoa do singular e predominância de nulos especialmente na $1^{\text {a }}$ pessoa do plural, como mostram os exemplos a seguir. Essa tendência difere do $\mathrm{PB}$, em que, embora haja altos índices de preenchimento pronominal para todas as pessoas (acima de 70\%), a primeira pessoa, especialmente

\footnotetext{
${ }^{7}$ A forma a gente é empregada, mas apenas com sentido impessoal/genérico, como veremos adiante.

${ }^{8}$ Um parecerista anônimo questiona a exclusão da desinência de $1^{\text {a }}$ pessoa do plural -mos no PB, que ainda continuaria sendo usada em algumas regiões. Enquanto é possível que haja alguma manutenção do pronome nós e do paradigma verbal a ele associado, especialmente através da escolarização, seguimos aqui diversos estudos, como os mencionados, que apontam uma grande preferência pela forma a gente associada à $3^{\text {a }}$ pessoa do singular, assim como também o emprego de nós com o paradigma verbal da $3^{\text {a }}$ pessoa do singular.
} 
do singular, é a que mais favorece o uso de nulos (BERLINCK; DUARTE; OLIVEIRA, 2015; DUARTE; SILVA, 2016).

(3) Eu plantava, eu fazia tudo isso, eu arava, eu plantava, eu recoía boniato...

(4) __ Brincávamo com materias que _ construíamo em casa, com tampinhas de botella, de plástico... Esses plástico __ formávamo nossos brinquedo.

O exemplo (3) mostra que o preenchimento da $1^{\text {a }}$ pessoa do singular ocorre mesmo num contexto sintático de coordenação de orações com sujeitos correferenciais, que favoreceria o aparecimento de sujeitos nulos. Já o exemplo (4) permite perceber que o PU apresenta sujeitos nulos em contextos sintáticos que favorecem fortemente o preenchimento no $\mathrm{PB}$, como relativas e estruturas com tópico marcado (GASQUE DE SOUZA; CHAVES; SIMIONI, 2018).

\subsection{SUJEITOS REFERENCIAIS}

Interessa particularmente o comportamento do sujeitos pronominais de terceira pessoa: no PU, diferente do PB, apenas referentes [+humanos] podem ser retomados por um pronome (embora, como ilustra (5b), possam ser retomados também por nulos); referentes [+animados, -humanos] (6a) e referentes [-animados] (6b) são retomados sistematicamente por sujeito nulo:

(5) a. Ela era minha professora. Ela sempre foi muito amiga minha. [...] E do meu ermão maior também, que o dia que ele saiu da escola... O dia da festa ela chorava como uma loca.

b. Um dia __ me deu uma paliza de vara porque __ me mandô carpí a cebola.

(6) a. Tempo de crescente, que as vaca se iam po mato, viste? As velha se agarravam com os animal, os ternero berrando, aí__ se atiravam a nado.

b. [...] aquela pezunhinha lá de vaca se dimanchava em vários pedazo de osso. Entonci__era as vaca.

c. Uma carroça com cavalo. Entonci _ vinha e levavam os surtidos pra um mês.

Esse traço separa claramente o PB, de um lado, do PU e do espanhol, pois enquanto nos últimos os sujeitos inanimados são categoricamente nulos, ${ }^{9}$ no PB podem ser retomados tanto por nulos quanto por pronomes. Segundo Duarte e Silva (2016), o PB mostra preferência pelo preenchimento de sujeitos [+humanos] em todos os contextos sintáticos, quer o antecedente esteja sintaticamente acessível ou não; além disso, quanto mais referencial for o sujeito ([+humano, +específico]), maior a probabilidade de preenchimento. Ainda assim, Berlinck, Duarte e Oliveira (2015) encontram 54\% de preenchimento com sujeitos [- humanos, animados].

Digno de nota, também, é o fato de serem raras no PU ocorrências como (7), com preenchimento de sujeitos correferenciais:

(7) Depois que eu embrabava com ele eu les dava uns tapa.

Novamente, tem-se uma diferença importante entre PU e PB. Duarte e Silva (2016) mostram que no PB há uma leve preferência pelo uso de nulos em sujeitos de orações encaixadas cujo antecedente é o sujeito da matriz, ou seja, quando há uma relação de ccomando. Também Berlinck, Duarte e Oliveira (2015) encontram, nesses casos, uma taxa de 68\% de sujeitos preenchidos.

\subsection{SUJEITOS DE REFERÊNCIA ARBITRÁRIA}

Os sujeitos de referência indeterminada são expressos preferencialmente pela $3^{\text {a }}$ pessoa do plural com sujeito nulo (8), como no PB, mas é frequente também a forma um impessoal (9), usada no espanhol:

\footnotetext{
${ }^{9}$ Conforme Duarte e Silva (2016) para o espanhol peninsular, porto-riquenho e argentino, Muniz (2017) para o espanhol uruguaio e Carvalho (2016) para o espanhol uruguaio falado por bilíngues PU/espanhol.
} 
(8) Não existia essas coisa que __ botam agora, não.

(9) a. Um sentava pra jantar na mesa e deus nos livre que um fosse dar uma palavra.

b. Os estranho são muito melhor que muitos da gente dum. Porque as vez um diz "ah, tudo bom, tudo", pero os estranho, bah! É muito meió.

Usam-se também, em menor proporção, a $3^{\text {a }}$ pessoa do singular acompanhada de se, a forma a gente, o pronome tu e, muito raramente, o verbo na $3^{\text {a }}$ pessoa do singular:

(10) Desse feijão miúdo que não se vê mais agora?

(11) Tem que sê, não hay que dá pelota como a gente hoje dá pelota pa isso, paquilo, não.

(12) Esse tempo era... tu tinha uma maestra só.

(13) O que _ usava era uma tal de... Uma fazenda que se chamava pelúcia.

Especificamente em relação às formas a gente e nós, nota-se uma especialização nos dados do corpus: nós é a forma pronominal de $1^{\text {a }}$ pessoa do plural (eu + outrem), enquanto a gente emprega-se com valor indeterminado/genérico, observação que corrobora os achados de Elizaincín (1992) e Bottaro (2009). Pacheco (2014) reporta a presença de a gente com referência à $1^{\text {a }}$ pessoa do plural no português uruguaio de Aceguá, mas em menor proporção do que nós; segundo a autora, trata-se de uma forma inovadora, favorecida por falantes mais jovens.

Vê-se, portanto, que o comportamento dos sujeitos pronominais no PU guarda diferenças consideráveis com o PB e, ao mesmo tempo, não reflete um sistema igual ao do espanhol. Na próxima seção, veremos que esse é o caso também em relação ao preenchimento dos objetos pronominais.

\section{OBJETOS PRONOMINAIS}

Os dados do corpus revelam que os objetos podem ser realizados como clíticos (55\%), como nulos (37\%) ou, ainda, como pronomes $\operatorname{retos}(8 \%)$ :

(14) Agalleta dura que chamavam de campaña, la comíamo um mês igual.

(15) Os que iam a cavalo soltavam _ no piquetezinho.

(16) A minha mãe primero fui casada cum um matrimônio [...] e despois ele dexô ela.

Observa-se no PU um uso produtivo do clítico de $1^{\text {a }}$ pessoa do plural, tanto em função acusativa quanto dativa:
a. Quando era criança que tinha treis ano o meu pai nos abandonô
b. ele foi quem nos conseguiu todo esse trabaio

Por outro lado, como evidenciam os números, são pouquíssimas as ocorrências de pronomes retos em posição de objeto. Além disso, em todos os casos observados no corpus, trata-se de pronomes de $3^{\text {a }}$ pessoa cujos referentes são [+humanos]; como veremos na seção 4.1, esse é mais um traço que diferencia PU e PB:
a. Eu entrevero elas.
[= duas irmãs]
b. E os uruguayos também tratam muito bem eles quando eles vierem aqui. [= os brasileiros]

Também, ao contrário do $\mathrm{PB}$, em que os clíticos de $3^{\mathrm{a}}$ pessoa foram majoritariamente substituídos pelas formas retas ou por nulos 
(NUNES, 1996; PAGOTTO, 1996), no PU esses clíticos ainda são produtivos. ${ }^{10}$ Cumpre observar que as formas acusativas encontradas no corpus são exclusivamente as espanholas $(l o(s), l a(s)),{ }^{11}$ enquanto os clíticos dativos alternam as formas brasileira lhe(s) e espanhola le(s):

(19) a. E ali a mamãe les deixava a farinha, la ensinava, ela fazia massa

b. Lhe fazia tudo, tudo nas mão

c. A carretel de linha lo partia ao meio e fazia o recado

A presença de formas espanholas para os clíticos acusativos, assim como a presença de formas brasileiras e espanholas para os clíticos dativos, pode remeter à concepção do português uruguaio como uma "mescla”. Em relação a isso, é preciso considerar que a presença de empréstimos do espanhol é esperada devido à situação de contato. Nesse sentido, Carvalho (2003, p. 126) argumenta que a interferência do espanhol sobre o PU se dá "[...] sobretudo a nível lexical”, afirmando que, como em "[...] outras situações de contato de línguas, a sintaxe, a morfologia, e a fonologia do português uruguaio também são mais resistentes à influência do espanhol, enquanto seu léxico é mais permeável" (CARVALHO, 2003, p. 131). A autora mostra que há vários tipos de transferências lexicais; entre eles estão os chamados empréstimos esporádicos, ou seja, empréstimos mais generalizados e menos frequentes, em relação aos quais pode-se, por vezes, detectar instabilidade (como ocorre com os clíticos dativos de $3^{\mathrm{a}}$ pessoa) - ainda que, como aponta Carvalho (2003), palavras gramaticais sejam emprestadas com menos frequência.

Além disso, essa tendência à manutenção da sintaxe, morfologia e fonologia das línguas em situação de contato fornece uma hipótese sobre a presença dos clíticos acusativos de $3^{\text {a }}$ pessoa no português uruguaio. Nunes (1996) defende que o desaparecimento dos clíticos acusativos de $3^{\mathrm{a}}$ pessoa no português brasileiro se deve à mudança na direção de cliticização do PB (de enclítico para proclítico) na passagem do século XIX para o século XX, com a qual, segundo o autor, os clíticos acusativos de $3^{\text {a }}$ pessoa ficam sem licenciamento do onset silábico. ${ }^{12}$ A partir disso, pode-se imaginar que as formas clíticas espanholas sejam emprestadas por terem características fonológicas que se adequam à pauta do português. Desse modo, o PU seguiria empregando clíticos acusativos de $3^{\mathrm{a}}$ pessoa, diferentemente do $\mathrm{PB}$.

\subsection{RETOMADA ANAFÓRICA}

A retomada de objetos anafóricos no PU é determinada pelo antecedente: antecedentes inanimados podem ser retomados por clíticos ou nulos, mas não por pronomes retos, ao passo que antecedentes humanos podem ser retomados por clíticos ou pronomes retos, mas não por nulos:

(20) a. De antes me lembro quando nós éramo soltera, loca por uma diversão, por um baile, que sempre faziam no fim de ano.

b. E le vistiu uma ropinha como bombacha [= no boneco]

a. e foi lá perto de Melo trazê-la nessa carroça. Recoiê ela com os fio pa trazê-la. [= a mãe]

b. porque despois que eu embrabava com ele eu les dava uns tapa, les botava de castigo, chamava eles tudo "plata, vayan a comprar algo al almacén!" [= os netos]

No PB, objetos nulos são favorecidos por antecedentes indefinidos/não específicos ou inanimados, mas com antecedentes animados, a tendência é de preenchimento - por clíticos, na fala culta mais monitorada, e por pronomes retos, na fala mais coloquial (CYRINO; NUNES; PAGOTTO, 2015). Crucialmente, no caso do PB, trata-se de uma tendência, ou seja, pode haver objetos nulos

\footnotetext{
${ }^{10}$ Uma hipótese a ser confirmada mediante ampliação do corpus diz respeito ao uso de clíticos de terceira pessoa por falantes mais velhos, uma vez que a informante mais jovem (37 anos) não os emprega, preferindo retomadas anafóricas com nulos.

${ }^{11}$ Nossos dados vão de encontro a Elizaincín, Behares e Barrios (1987), que não encontram clíticos acusativos de $3^{\text {a }}$ pessoa (nem formas espanholas, nem formas portuguesas) em seu corpus.

${ }^{12}$ Para mais detalhes, ver Nunes (1996).
} 
com antecedentes animados e definidos/específicos, assim como pode haver retomada por pronome reto com antecedentes inanimados. No caso do PU, os dados evidenciam uma especialização de formas relacionada ao traço [+/-humano] do referente, de modo que antecedentes [+humanos] não são retomados por nulos, e antecedentes [-animados] não são retomados por pronomes retos. No espanhol, de modo geral, o uso de pronomes retos em posição de objeto não ocorre, ${ }^{13} \mathrm{e}$ a possibilidade de objetos nulos é bem mais restrita do que no PB (CYRINO, 2016).

\subsection{COLOCAÇ̃̃O DOS CLÍTICOS}

É sabido que a posição dos clíticos no PB é predominantemente proclítica com verbos simples e proclítica ao verbo principal em locuções verbais (PAGOTTO, 1996; PETROLINI JUNIOR., 2014). No espanhol, a colocação pronominal responde à forma verbal: com verbos simples, ocorre próclise com verbos no indicativo, subjuntivo e imperativo negativo e ênclise com gerúndio, particípio e imperativos afirmativos (PETROLINI JUNIOR., 2014; RAE, 2014).

A colocação com formas verbais simples nos dados do PU apresenta próclise categórica a verbos flexionados ${ }^{14}$ como mostram os exemplos (14), (17) e (19) acima, ou seja, comportamento análogo ao do PB. Contudo, a observação dos padrões de colocação com as demais formas verbais evidencia um sistema distinto tanto do PB quanto do espanhol: embora haja poucas ocorrências no corpus, tem-se ênclise categórica com imperativos (22) e próclise categórica com gerúndios (23). Já os clíticos que acompanham infinitivos podem variar de posição, com leve predomínio de ênclise $(24,25)$ :

$$
\text { b. Imaginate tu. }
$$

(23) Tudo mundo me abrazando, me beijando.

(24) a. [um tio meu] foi lá perto de Melo trazê-la nessa carroça.

b. Ai, como é o nome, eu tenho que dizerte o nome!

(25) a. E se vinha um moço te convidá pa dançá e tu dizia que não, deus nos livre e guarde!

b. Não sei nem te explicá.

Em sequências verbais, a colocação dos clíticos no PB é sistematicamente em próclise ao verbo principal (PAGOTTO, 1996; PETROLINI JUNIOR., 2014). No caso do espanhol, com perífrases verbais o clítico pode permanecer enclítico ao verbo principal infinitivo ou gerúndio, bem como anteceder o verbo principal; com sequências verbais não perifrásticas, o clítico tende a acompanhar o verbo que o seleciona (PETROLINI JUNIOR., 2014), mas pode ocorrer subida de clíticos com verbos de reestruturação (ZAGONA, 2002; RAE, 2014).

Nos dados do corpus, a subida de clíticos é categórica com locuções verbais $(26),{ }^{15}$ ocorrendo também com clíticos em função de sujeito com verbos causativos (27), como no PB: ${ }^{16}$

(26) a. pero todo mundo me vem saludá porque me conhecem

b. porque me tenho relacionado com gente que tá bem

c. foi e falou o meu pai que le tinham dito que eu criava todo meus irmão e que eu fazia tudo

d. Nóis brincávamo assim ó, eu te vô dizê

\footnotetext{
${ }^{13}$ Muniz (2017), em seu levantamento com dados do espanhol de Rio Branco, não encontra ocorrências desse tipo com nenhuma pessoa gramatical.

${ }^{14}$ Há apenas duas exceções em todo o corpus:

(i) faziale tudo, pero não sei por que era assim.

(ii) Eu não sei como não quebrole a mão.

${ }^{15}$ Madeira (2018) mostra que também ocorre subida de clítico nesses contextos nos dados de Bottaro (2009).

${ }^{16}$ A subida do clítico, nesses casos, é obrigatória no português (RAPOSO, 2013).
} 
e. Agora quem se vai animá a entrá no mato?

a. A minha mãe não me deixava ir

b. Se me mandam planchá ropa o me mandam fazê algo, que faço eu?

Há também um único caso de subida de clítico em sequências não perifrásticas: ${ }^{17}$

Então pedimo aí na junta si le mandavam acomodá.

Por fim, o PU apresenta redobro de clíticos, fenômeno característico da língua espanhola (FANJUL, 2014). No entanto, assim como a subida de clíticos, o redobro parece ser mais restrito do que no espanhol: na maioria dos casos, o elemento dobrado é um pronome reto, mas também ocorrem no corpus casos de redobro de SNs.

\section{a. Entonci nos favorece a nós.}

b. Me dá a impressão a mi que a gente brasilera é mais [amável].

c. Um dia houve um baile na escola e le disseram pra ela assim: "Cinchá la cisterna, cinchá la cisterna!"

[a maestra] veio e le pediu o meu pai, foi e falou o meu pai que le tinham dito que eu criava todo meus irmão

\section{CONSIDERAÇÕES FINAIS}

Os dados apresentados evidenciam que a gramática do PU e a gramática do PB são distintas, ao menos no que diz respeito ao preenchimento do sujeito e do objeto pronominais. Em relação ao preenchimento de sujeito, o PU parece estar no meio do caminho entre o espanhol, língua de sujeito nulo, e o $\mathrm{PB}$, que apresenta clara tendência não pro-drop. Ainda que os paradigmas flexionais de PU e espanhol uruguaio sejam muito semelhantes, apresentando apenas um sincretismo, entre $2^{\text {a }}$ e $3^{\text {a }}$ pessoas do plural, e que o PU apresente características compatíveis com línguas de sujeito nulo, as taxas de preenchimento pronominal dos sujeitos são consideravelmente mais elevadas no PU do que nessas línguas.

Em relação à posição de objeto, chamam a atenção o fato de o $\mathrm{PU}$ contar com um sistema produtivo de clíticos de $3^{\mathrm{a}}$ pessoa e as "restrições de humanidade" que regulam a retomada anafórica - outro ponto de divergência em relação ao PB. É digno de nota o fato de que tanto na posição de sujeito quanto na posição de objeto os pronomes retos de $3^{\text {a }}$ pessoa são empregados apenas com referentes [+humanos]; trata-se, portanto, de um sistema de pronomes fortes, diferente do $\mathrm{PB}$, que tem um sistema de pronomes fracos homófonos (cf. Kato, 1999). Na posição de objeto, referentes inanimados são retomados preferencialmente com nulos, enquanto sujeitos de referência arbitrária são sempre nulos. Os clíticos parecem ter uma maior flexibilidade quanto à referência, podendo retomar tanto referentes animados quanto inanimados. Também a sintaxe da colocação não corresponde à do $\mathrm{PB}$, tampouco à do espanhol, ainda que ocorram construções tipicamente associadas ao espanhol, como a subida e o redobro de clíticos.

Conclui-se, portanto, que há diferenças significativas entre as gramáticas de PU e PB, corroborando a hipótese de que o PU constitui um sistema gramatical independente, diferente tanto do PB quanto do espanhol. Nesse sentido, faz-se necessário investigar os fatores condicionantes da realização do sujeito como nulo ou como pronome, bem como os fatores condicionantes da escolha entre clítico e pronome reto, no caso dos referentes [+humanos], e entre clítico e nulo, no caso dos referentes [-humanos], além da própria natureza do objeto nulo. Esses serão os próximos passos de nossa investigação.

\section{REFERÊNCIAS}

BEHARES, L. Portugués del Uruguay y educación fronteriza. In: BROVETTO, C.; GEYMONAT, J.; BRIAN, N. (org.) Portugués del Uruguay y educación bilingüe. Montevideo: ANEP, 2007. p. 99-171.

${ }^{17}$ Note-se que, embora o verbo matriz seja causativo, o clítico le não é sujeito, mas sim objeto de acomodar. 
BERLINCK, R.; DUARTE, M. E.; OLIVEIRA, M. Predicação. In: KATO, M.; NASCIMENTO, M. (org.). A construção da sentença. São Paulo: Contexto, 2015. p. 81-149.

BOTTARO, S. O sujeito pronominal no português uruguaio da região fronteiriça Brasil-Uruguai. 2009. 217 f. Tese (Doutorado em Letras) - Departamento de Línguas Modernas, Faculdade de Filosofia, Letras e Ciências Humanas, Universidade de São Paulo, São Paulo, 2009.

CARVALHO, A. M. Rumo a uma definição do português uruguaio. RILI, v. 1, n. 2, p. 125- 149, 2003.

CARVALHO, A.; BESSETT, R. Subject pronoun expression in Spanish in contact with Portuguese. In: CARVALHO, A.; OROZCO, R.; SHIN, N. (org.). Subject pronoun expression in Spanish. Washington, D.C.: Georgetown University Press, 2015. p. $143-166$.

COSTA, J.; FIGUEIREDO SILVA, M. C. Nominal and verbal agreement in Portuguese: an argument for Distributed Morphology. In: (org.). Studies on agreement. Amsterdam: John Benjamins, 2006. p. 25-46.

CYRINO, S. The null object in Romania Nova. In: KATO, M.; ORDONEZ, F. (org.). The morphosyntax of Portuguese and Spanish in Latin America. New York: Oxford University Press, 2016. p. 177-203.

CYRINO, S.; NUNES, J.; PAGOTTO, E. Complementação. In: KATO, M.; NASCIMENTO, M. (org.). A construção da sentença. São Paulo: Contexto, 2015. p. 37-80.

DUARTE, M. E.; SILVA, H. S. Microparametric variation in Spanish and Portuguese. In: KATO, M.; ORDONEZ, F. (org.). The morphosyntax of Portuguese and Spanish in Latin America. New York: Oxford University Press, 2016. p. 1-26.

ELIZAINCÍN, A. Algunas precisiones sobre los dialectos portugueses en el Uruguay. Montevideo: UdelaR, 1979. . Análisis de la variabilidade de los DPU. In: Dialectos en contacto. Montevideo: Arca, 1992. p. 95-156.

ELIZAINCÍN, A.; BEHARES, L.; BARRIOS, G. Nos falemo brasilero: Dialectos portugueses en Uruguay. Montevideo: Amesur, 1987.

FANJUL, A. P. Conhecendo assimetrias: a ocorrência de pronomes pessoais. In: FANJUL, A. P.; GONZÁLEZ, N. M. (org.). Espanhol e português brasileiro: estudos comparados. São Paulo: Parábola, 2014. p. 29-50.

GASQUE DE SOUZA, K.; CHAVES, L.; SIMIONI, L. Sujeitos nulos no português uruguaio. PAPIA, São Paulo, v. 28, n. 1, p. 7-24, 2018.

KATO, M. Strong pronouns, weak pronominals and the null subject parameter. PROBUS, v. 11, n. 1, p. 1-37, 1999.

KATO, M.; DUARTE, M. E. O sujeito no português brasileiro e sua tipologia. In: PILATI, E.; SALLES, H.; NAVES, R. (org.). Novos olhares para a gramática do português brasileiro. Campinas: Pontes, 2017. p. 13-42.

MADEIRA, M. "Eu te vou dizê" como é a colocação dos clíticos no português uruguaio. 2018. 30 f. Trabalho de Conclusão de Curso (Licenciatura em Letras - Português, Espanhol e suas respectivas Literaturas) - Universidade Federal do Pampa, Jaguarão, 2018.

MUNIZ, S. "Nas casa sempre em brasilero": o preenchimento de sujeitos e objetos no PU de Poblado Uruguay. 2017. 77 f. Trabalho de Conclusão de Curso (Licenciatura em Letras - Português, Espanhol e suas respectivas Literaturas) - Universidade Federal do Pampa, Jaguarão, 2017. 
NUNES, J. M. Direção de cliticização, objeto nulo e pronome tônico na posição de objeto em português brasileiro. In: ROBERTS, I.; KATO, M. (org.). Português brasileiro: uma viagem diacrônica. 2. ed. Campinas: Editora da UNICAMP, 1996. p. $207-222$.

PACHECO, C. Primeiras reflexões sobre o português fronteiriço de Aceguá. In: CARDOSO, C. R. et al. (org.). Variação linguística: contato de línguas e educação. Campinas: Pontes, 2013.p.187-207.

PAGOTTO, E. G. Clíticos, mudança e seleção natural. In: ROBERTS, I.; KATO, M. (org.). Português brasileiro: uma viagem diacrônica. 2. ed. Campinas: Editora da UNICAMP, 1996. p. 223-261.

PETROLINI JUNIOR, C. D. Colocação dos pronomes clíticos. In: FANJUL, A. P.; GONZÁLEZ, N. M. (org.). Espanhole português brasileiro: estudos comparados. São Paulo: Parábola, 2014. p. 51-71.

RAE. Nueva gramática de la lengua española. Manual. 4. ed. Buenos Aires: Espasa, 2014.

RAPOSO, E. P. Gramática do português. Lisboa: Fundação Calouste Gulbenkian, 2013.

URUGUAY. Instituto Nacional de Estadística. Censo Demográfico. 2011. Disponível em: http://www.ine.gub.uy/censos-2011. Acesso em: 24 mar. 2018.

ZAGONA, K. The syntax of Spanish. Cambridge: Cambridge University Press, 2002.

\section{(c) (1) $\circledast$}

Recebido em 21/09/2018. Aceito em 18/12/2018. 